\title{
International Expansion of the Use of Pharmacotherapies for the Treatment of Opioid Dependence
}

\section{Thomas F. Kresina ${ }^{1 *}$, R. Douglas Bruce ${ }^{2}$, Sandrine Pirard ${ }^{1}, K_{\text {Kevin Mulvey }}^{1}$, Ricardo Sanchez Huesca ${ }^{3}$ and Robert Lubran ${ }^{1}$}

${ }^{1}$ Division of Pharmacologic Therapies, Center for Substance Abuse Treatment, Substance Abuse and Mental HealthServices Administration, Rockville, Maryland, USA ${ }^{2}$ Yale School of Medicine, Yale School of Public Health, New Haven Connecticut, USA

${ }^{3}$ Centros de Integracion Juvenil, Mexico, D.F, USA

\begin{abstract}
Until recently, the global availability and consumption of opioid agonists and psychotropic medications have been below the levels needed for research to demonstrate local efficacy and to develop local evidence-based best medical practices. In addition, the global availability and use of opioid agonists and psychotropic medications have not been sufficient to implement the well documented efficacy shown for the treatment of opioid dependence that has been developed by research over the last 40 years. This strong research base has resulted in the development of evidencebased medical practices, such as Medication Assisted Treatment (MAT) for opioid dependence. The recognition of MAT as an effective medical treatment for opioid abuse and dependence has resulted in a substantial global increase in the medical use of opioid agonists and psychotropic medications to address opioid dependence. This increase is particularly evident in the initiation of new MAT programs in regions of Europe, North America, Africa, Asia and Oceania. While in other regions of the world, the medical use of opioid agonists and psychotropic medications have not substantially increased, the implementation of MAT programs have begun as part of the global effort to reduce HIVIAIDS. These HIV prevention programs have utilized MAT as an element of programs that target injection drug users to reduce their risk of both acquiring and transmitting HIV infection. Thus, this article documents the recent international expansion of the use of MAT for opioid dependence as a result of efforts to increase access and availability of evidence based treatments for opioid dependence as well as efforts to reduce the spread of infectious diseases, such as HIVIAIDS.
\end{abstract}

Keywords: Medication assisted treatment; Methadone; Buprenorphine; Naltrexone; Opioid dependence

\section{Introduction}

Drug abuse and dependence is a major public health problem that continues to grow in significance [1]. The global increase in opioid abuse and dependence is particularly significant. Opioid abuse and dependence is increasing because of the availability of opioids through increased global trafficking of heroin, the widespread increase in use of opioid analgesics in the treatment of chronic pain as well as in acute pain management, and the novel use of opioids as base components of designer drugs [2-4]. Opioids are neurobiologically rewarding compounds with a great potential to lead to a substance use disorder in opioid users.

Substance use disorders are defined in the Diagnostic and Statistical Manual of Mental Disorders, Fourth Edition [5] as substance abuse and substance dependence. Opioid abuse and dependence are chronic, relapsing diseases that can be successfully treated. But, they are also complex physiologic, social, and behavioral disorders that often coexist with psychiatric illness, as well as, co-morbid medical infectious diseases such as HIV, hepatitis virus $\mathrm{B} / \mathrm{C}$ or tuberculosis [6,7]. Thus, opioid abuse and dependence are most effectively treated through comprehensive medical, social, psychological and rehabilitative services that address all the needs of the individual. MAT is the use of effective medications in combination with behavioral therapies and is a highly effective treatment for opioid abuse and dependence [8]. MAT impacts public health through the reduction of opioid use, opioid overdose mortality and transmission of infectious diseases when implemented on a national scale [9].

\section{The Pharmacotherapies Comprising Medication As- sisted Treatment}

Globally, the predominant pharmaceuticals used as MAT in either detoxification or maintenance treatment are the opioid agonists, methadone and buprenorphine (Table 1). Methadone and buprenorphine are opioid agonist narcotic medications and, as such, are internationally regulated by international drug control conventions. The International Narcotics Control Board (INCB) monitors the implementation by national governments of the international drug control conventions. The goal of the INCB monitoring is to insure a sufficient supply of opioid agonists and psychotropic medications for their use in both scientific research and medical application [10] Governments must have monitoring and control systems in place to ensure that opioid agonists and psychotropic medications are used solely for legitimate medical purposes [11]. These legitimate medical applications include the treatment of severe or chronic pain as well as use in MAT. The use of opioid analgesics for pain management has risen substantially over the last ten years. Their diversion and illicit use has resulted in a substantial increase in opioid dependence and the increased need for the use of MAT to address opioid dependence resulting from illicit opioid analgesic abuse.

\section{Methadone}

Methadone is an opioid agonist that has demonstrated safety and

*Corresponding author: Thomas F. Kresina ,PhD, Division of Pharmacologic Therapies, Center for Substance Abuse Treatment, Substance Abuse and Mental Health Services Administration, Choke Cherry Road, Rockville, Maryland 20857, USA, E-mail: Thomas.Kresina@samhsa.hhs.gov

Received December 01, 2011; Accepted December 14, 2011; Published December 17, 2011

Citation: Kresina TF, Bruce RD, Pirard S, Mulvey K, Huesca RS, et al. (2012) International Expansion of the Use of Pharmacotherapies for the Treatment of Opioid Dependence. Clin Exp Pharmacol S5. doi:10.4172/2161-1459.S5-001

Copyright: (c) 2012 Kresina TF, et al. This is an open-access article distributed under the terms of the Creative Commons Attribution License, which permits unrestricted use, distribution, and reproduction in any medium, provided the original author and source are credited. 
efficacy in the treatment of heroin abuse and dependence for over forty years and more recently in the treatment of prescription opioid abuse and dependence $[12,13]$. In most countries that utilize MAT for the treatment of opioid dependence, methadone is the pharmacotherapy of choice [14]. Methadone is usually the least expensive medication and when used in evidence-based treatment paradigms is cost effective and can result in reduced drug use and improvements in quality of life $[15,16]$. As such, it is a highly effective HIV prevention intervention when implemented nationally [14,17]. Methadone is a synthetic $\mu$-opioid receptor agonist with pharmacological properties qualitatively similar to morphine and was originally used to treat the painful symptoms of withdrawal from heroin and other opioids $[18,19]$. Administered daily as an oral dose for the treatment of opioid dependence, an individual therapeutic dosage is determined to maintain an asymptomatic state and stabilize a patient, without episodes of opioid overmedication or withdrawal. Minimum retention time in treatment varies for residential and outpatient methadone treatment programs. The National Institutes of Health consensus panel [20] concluded that individuals treated for fewer than three months with methadone do not show substantial medical gain. Methadone treatment is effective as both primary and secondary HIV prevention [21] and cost-effective to society [15,22]. In addition to improving health outcomes, methadone treatment also substantially improves the quality of life of patients over the course of treatment. Relapse to opioid use is common when methadone is discontinued without further support or behavioral treatment.

\section{Buprenorphine}

Buprenorphine is a partial opioid agonist that has been shown to be safe and effective in the treatment of both heroin use and prescription analgesics abuse and dependence $[23,24]$. Buprenorphine, a partial mu-receptor opiate agonist [25], differs significantly from full agonists. Most significantly, buprenorphine has a plateau of its agonist properties at higher doses resulting in an improved safety profile compared with a full agonist. Specifically, buprenorphine has a favorable 'ceiling effect' on respiratory depression precluding overdose potential [26]. However, the abuse of other substances, such as benzodiazepines, may enhance respiratory depression and remains a contraindication with the use of opioid agonists. Improved safety and thrice weekly flexible dosing of buprenorphine promotes patient acceptance. In addition, buprenorphine has two features that decrease street diversion: buprenorphine can precipitate opiate withdrawal when taken by an opioid dependent patient [27] and buprenorphine can be marketed alone (Subutex ${ }^{\circledR}$ ) or in combination with naloxone $\left(\right.$ Suboxone $\left.{ }^{\circledR}\right)$. In the latter formulation, if it is crushed and injected, opioid withdrawal symptoms may occur which may be a disincentive for diversion [28]. The improved safety profile and the treatment availability through primary care remain popular with patients and reduces stigma; however, opioid dependent patients can fail buprenorphine maintenance treatment, and should be subsequently offered methadone maintenance treatment.

Other buprenorphine formulations- To address the issues of adherence, diversion and nonmedical use of buprenorphine, an extended-release, implantable formulation has been developed. This formulation is a polymeric matrix composed of ethylene vinyl acetate and buprenorphine that provides an initial pulse release of buprenorphine followed by six months of constant slow release of buprenorphine. In a recently completed randomized clinical trial in the United States [29], patients were initially induced using oral buprenorphine and then required to receive a fixed dose of $12-16 \mathrm{mg} / \mathrm{d}$ of Suboxone ${ }^{\circledR}$ for three days prior to receiving the sub-dermal implant. Patients were supplemented with Suboxone ${ }^{\circledR}$ after implantation, if necessary. The clinical trial may lead to the application for United States Food and Drug Administration approval sometime in 2013. Although this remains an advance for pharmacotherapy, treatment retention issues may arise. It may be difficult to retain individuals in behavioral therapy, if they only need to see a medical provider twice a year for their substance abuse treatment pharmacotherapy. Additionally, since buprenorphine has a higher binding affinity to the mu-opioid receptor, if the patient needs to change to a full agonist such as methadone, implanted buprenorphine will block the full agonist from accessing the receptor site, unless the implant is surgically removed.

\section{Naltrexone}

Naltrexone is a non-narcotic, prescription medication for use in relapse prevention to opioid use. Naltrexone is a long-acting, opioid antagonist that blocks the euphoric effects of opioids binding the $\mathrm{mu}$ opioid receptor [30]. Unlike methadone, there is no negative reinforcement (opioid withdrawal) upon discontinuation. Due to naltrexone's opioid antagonism, patients must abstain from opioids for a minimum of seven days prior to starting naltrexone treatment to avoid the precipitation of opioid withdrawal. Naltrexone is most effective when utilized subsequent to the medical detoxification from opioids. The effectiveness of naltrexone treatment depends upon patient motivation and a social support system that promotes medication adherence [31]. Thus, in scenarios where there is strong family or social support for the patient in care, oral naltrexone has been shown to be effective in the prevention of relapse to heroin use [32]. Because of the need for adherence support interventions, the most recent Cochrane review of oral naltrexone treatment for relapse prevention to opioid use commented that oral naltrexone has not been scientifically demonstrated to be superior to other forms of treatment for opioid dependence [33].

Depot-naltrexone $\left(\right.$ Vivitrol $\left.^{\circledR}\right)$ addresses the reduced medication adherence of oral naltrexone through a monthly injectable formulation. Increased medication adherence was shown in a recent Phase 3 clinical trial that confirmed Vivitrol's safety and efficacy in the prevention of relapse to heroin use in a cohort of injection drug users [34]. A higher retention in care and higher rates of opioid-free urine screens were observed along with a significant reduction in opioid craving compared to placebo. Currently, studies are underway to determine the most efficacious service model(s) for the use of depot-naltrexone in the treatment of relapse prevention to heroin use. Vivitrol ${ }^{\circledR}$ was approved in the United States in 2010 for the treatment of opioid abuse and dependence and in the Russian Federation in 2011.

Other naltrexone formulations- Extended release naltrexone implants have been developed to provide long lasting, two-tosix months, continuous release of medication. They are surgically implanted subcutaneously in the arm or abdominal wall. An implant containing $1 \mathrm{~g}$ of naltrexone compounded with magnesium stearate releases naltrexone at levels above $1 \mathrm{ng} / \mathrm{mL}$ for 30-60 days [35]. Another implant approved for treatment of opioid dependence in the Russian Federation contains $1 \mathrm{~g}$ of naltrexone that provides serum medication levels above $20 \mathrm{ng} / \mathrm{mL}$ [36]. This implant has been shown to be effective in reducing illicit heroin use in injection drug users [37]. A third implant formulation contains a poly-lactic-based polymer and naltrexone at doses of 1.1, 2.2, or $3.3 \mathrm{~g}$. In this formulation, naltrexone 
release has been shown to be $1-2 \mathrm{ng} / \mathrm{mL}$, for 3 and 5 months extending to 7 months [38,39].

\section{Additional Pharmacotherapies and Treatment Para- digms}

Additional medications are used on a country-by-country basis, mostly in private clinics and on a fee for service basis. These medications can provide an alternative for individuals who may not be interested in attending public treatment programs provided by the government, or who have not been successful in public treatment programs. These medications include ibogaine, baclofen, and modafinil singularly, or the combination of clonidine, lorazepam, trazodone and a stimulant in combination [40-43]. These medications have shown efficacy only in clinical trials. Other treatment paradigms shown in pilot clinical trials include the use of slow-release oral morphine (Substitol ${ }^{\circledR}$ ) [44], hydromorphone and diacetylmorphine [45]. Heroin-assisted treatment programs have been studied in Austria, Belgium, Canada, France, Germany, Spain, Switzerland, the United Kingdom and the Netherlands [46].

\section{Expansion of the use of Pharmacotherapies and Medication Assisted Treatment}

\section{North america}

The united states: In the United States, research studies have developed and shown that the most efficacious treatment for opioid abuse and dependence comprises medical treatment programs that utilize pharmacotherapies and include psychosocial counseling, financial, legal, educational services as well as wrap around social services [47]. Federal programs catalogue such evidence-based best medical practices and promote their implementation in the care and treatment of patients [48]. Good medical outcomes are optimized through the education and training of health care providers with evidence-based medical practices. Federal programs can also support the piloting of treatment improvement projects to develop national implementation strategies. Drug treatment programs that utilize methadone in the United States are regulated by the federal government for their adherence to treatment standards by accreditation and in their record keeping requirements for use of controlled pharmaceuticals $[49,50]$.

Methadone: In the United States, the use of methadone for the treatment of heroin dependence is allowed only in specialized treatment programs, called Opioid Treatment Programs (OTPs). They are regulated by the Center for Substance Abuse Treatment (CSAT), Substance Abuse and Mental Health Services Administration (SAMHSA) [51]. There are approximately 1,250 certified OTPs in 47 States, the District of Columbia, Puerto Rico and the Virgin Islands. Over $90 \%$ of these facilities offer outpatient addiction treatment facilities, while approximately $10 \%$ of OTPs are residential (nonhospital) treatment facilities, $10 \%$ of OTPs are hospital based treatment programs outpatient units and 5\% of OTPs are outpatient community health/mental health facilities.

Three of the OTPs offer maintenance treatment with only buprenorphine. SAMHSA requires all OTPs to be accredited including programs only offering detoxification, either in a hospital, residential or outpatient setting. Many OTPs offer both methadone dosage tapering and long term maintenance. The federal government's goal in the regulatory process is to bring health care services to individuals in need of treatment, through a series of regulatory activities that promote treatment efficacy and limit methadone diversion.

A state-by-state profile of OTP's is produced by SAMHSA that includes: the number of patients in treatment, the types of treatment services provided, the location of treatment programs with-in each state, organization that performs accreditation, business ownership of the OTPs, and the types of payments for services the treatment programs accept [52]. Overall, OTP's treat approximately 300,000 individuals with approximately $40 \%$ of patients in treatment for longer than two years [50].

In the past two decades, OTP expansion has taken place mostly in the private for-profit sector in the United States, especially in areas where there is high incidence of prescription opioid abuse. This may be due to the lack of public funding made available from States or localities, while demand for services grows.

Buprenorphine: Buprenorphine is a Schedule III partial opioid agonist that allows for qualified and specially licensed physicians to treat patients with opioid addiction in a primary care setting. In the United States, two sublingual formulations (Suboxone ${ }^{\circledR}$, Subutex ${ }^{\mathbb{B}}$ ) are used for office-based treatment of opioid dependence. The introduction and expansion of office-based opioid treatment using buprenorphine provides another option for patients with opioid dependence. This expansion of treatment capacity attempts to address the limited access to methadone due to methadone restriction to OTPs [53]. While the Drug Addiction Treatment Act of 2000 included OTPs as venues to utilize buprenorphine in the treatment of opioid dependence, less than $1 \%$ of patients in treatment in OTPs receive buprenorphine due, predominantly, to the higher cost of buprenorphine compared to methadone.

SAMHSA provides an online physician and treatment program locator at: http://buprenorphine.samhsa.gov/bwns_locator/. In addition, SAMHSA provides a state-by-state profile of the locations of qualified physicians who prescribe buprenorphine [54]. Buprenorphine treatment of opioid abuse and dependence is reviewed in Treatment Improvement Protocol 40 [55].

Since 2003, over 29,500 physicians and other health care professionals in the United States have been trained in detoxification and long term treatment with buprenorphine. Over 22,100 physicians qualify to prescribe buprenorphine. However, capacity for increased buprenorphine prescribing among trained and waivered physicians exists due to physician, patient and institutional barriers [56-58]. Still, since the approval of Suboxone ${ }^{\circledR}$ and Subutex ${ }^{\circledR}$ in 2002 , over one million patients in the United States have been prescribed buprenorphine for the treatment of opioid dependence. Physician and patient surveys following the introduction of buprenorphine treatment for opioid dependence suggest that patients were not being shifted from one modality, methadone treatment, to another [53]. However, the high percentage of individuals dependent on non-heroin opioids receiving buprenorphine treatment in primary care clearly demonstrates the increasing problem of prescription opioid abuse in the United States. It also indicates that office based treatment may be a more attractive alternative than a traditional OTP and may encourage those unwilling to attend an OTP to seek and accept treatment. Thus, buprenorphine treatment provides a response to the increase in prescription opioid abuse. It allows a new population of individuals not receiving treatment through OTPs to be reached. Understanding these positive results warrants the continued expansion of MAT services in primary care. 
Models to implement buprenorphine in HIV clinical settings have also been piloted [59]. The Health Resources and Services Administration (HRSA) supported a five year Special Project of National Significance (SPNS) for buprenorphine in ten demonstration sites. A special issue of the Journal of the Acquired Immune Deficiency Syndrome was published providing a comprehensive analysis of the project [60].

Naltrexone: Because of the lack of positive reinforcing effects using naltrexone, low motivation resulting in low medication adherence on the part of many patients, poor retention in treatment, as well as, poor clinician acceptability, oral naltrexone is not as widely prescribed for treatment of opioid dependence in the United States. Some states, however, such as Missouri, show a preference for naltrexone and Vivitrol ${ }^{\circledR}$ as a treatment option. In such states there is active advocacy for non-narcotic treatment options. In addition, penal systems and drug courts have shown an interest in the use of Vivitrol ${ }^{\mathbb{R}}$. Initial bulk purchases of Vivitrol ${ }^{\circledR}$ have been made by judicial programs and their use will help the development of evidence-based best practices allowing for the continued expansion of MAT.

Mexico: Mexico is party to the 1961 United Nations (UN) Single Convention on Narcotic Drugs, as amended by the 1972 Protocol, the 1971 UN Convention on Psychotropic Substances, and the 1988 UN Drug Convention. Mexico also subscribes to regional counter narcotics commitments, including the 1996 Anti-Drug Strategy in the Hemisphere and the 1990 Declaration of Ixtapa [61]. Mexico, in 2009, decriminalized the possession of small amounts of marijuana, cocaine, heroin, and methamphetamine. Mexico's retail-level narcotics distribution (narcomenudeo) law does not mandate legal action against individuals in possession of minimal amounts of drugs until their third offense. However, drug use is rising in Mexico. Mexico remains a source country of heroin for domestic use and transit into the United States [61]. Domestically, two populations are most at-risk, teenagers and senior citizens. National surveys of drug use trends undertaken by Mexico's Secretary of Health have documented the decline in the age of initiation to 8 -/10-year-olds. Heroin abuse is most prevalent along the border with the United States and in Mexico's major cities. The state of Baja California has a particularly severe problem, centered in Tijuana. The Encuesta Nacional de Adicciones of 2008 (2008 Addictions National Survey of general population households) reported a usage of heroin at $0.01 \%$ in the last month [62]. In that survey, it was noted that senior citizens tend to abuse opioid prescription drugs. Federal health officials coordinate prevention, treatment and rehabilitation programs through a variety of avenues, including state and municipal governments, ancillary federal entities and non-governmental organizations. The national coordination body is the National Council Against Addiction (CONADIC) with priorities including; standardizing drug counseling curricula, increasing the availability of rehabilitation services in the penitentiary system, and establishing Drug Free Community Coalitions to expand citizen participation in the prevention of drug use [63]. There is also a growing focus on comprehensively improving the life of youth in high risk areas such as Ciudad Juárez, where drug traffickers often pay associates in drugs. The long-established and highly respected organization Centros de Integracion Juvenil (CIJ) is expanding its inpatient treatment centers in underserved areas of Ciudad Juárez [64]. It is under this improving effort to address drug abuse that drug treatment clinics, including methadone programs, have become targets in the drug war currently ongoing in Mexico.
Methadone: In Mexico, methadone is the medication used in the majority of opioid treatment programs. Methadone treatment is available in major cities and treatment programs are operated by Profesionales Contra la Adiccion (PCA) and Asistencia Media Contra la Adiccion (AMCA) with AMCA being a subdivision of PCA. AMCA staffs methadone clinics in Sonora and Sinaloa $[65,66]$. Until recently, the consumption of heroin was confined to the northwestern border region with the United States; currently heroin use has spread to the central and southern parts of the country. The proportion of individuals seeking treatment due to their heroin consumption is relatively low with only $14 \%$ of the heroin users reported seeking therapeutic services.

Treatment of opioid dependence utilizing methadone in detoxification or maintenance treatment has existed privately since 1970. Due to the need for treatment, the initial government methadone clinic was opened by CIJ in 2001 at Ciudad Juarez, Chihuahua. In 2008 , CIJ treatment services units show a $12.1 \%$ of patients were active users in the previous month [64]. A second program opened in the city of Tijuana, Baja California, in 2009. For 2012, it is planned to open another CIJ treatment unit in Mexicali, Baja California. The demand of treatment services at Ciudad Juárez results in a daily average of 140 patients receiving methadone. The City of Tijuana treatment program has a daily average of 69 patients. Both units are open 365 days a year [64]. With the current epidemic of heroin and other opioid use in Mexico, dramatic expansion of MAT is necessary to address the ongoing opioid use.

The CIJ Program of Maintenance and Cessation with methadone is offered as an alternative to heroin. Short and long term methadone treatment is directed to reduce the consumption of heroin, with the goal of rehabilitation of the users. Methadone treatment programs are based in clinics and seven regional hospital programs. The initial evaluation of methadone treatment efficacy of the program occurred in 2003 with an evaluation of clinical outcomes for 44 patients at Ciudad Juárez. The researchers found that $91 \%$ of the patients were diagnosed with a severe heroin dependency during the initial phase of the treatment; however, with continued methadone treatment in the next phases only two patients presented with severe heroin or other substances dependency [64].

Buprenorphine: Buprenorphine is available in Mexico for purchase from pharmacies as well as over the internet [67]. Prescriptions for buprenorphine can be obtained from physicians in specific hospitals but may not be required for purchase at pharmacies.

Canada: Canada is party to the 1988 UN Drug Convention, and a member of the UN Commission on Narcotic Drugs. Currently, it is estimated that there are approximately 125,000 opioid dependent individuals in Canada with roughly 20,000 individuals currently receiving treatment [68]. Delivery of demand reduction, education, treatment and rehabilitation is primarily the responsibility of the provincial and territorial governments with Health Canada providing funding for these services. Health Canada has provided treatment guidelines for the use of pharmacotherapies in the treatment of opioid dependence [69], but local treatment guidelines can update the older national guidelines.

Methadone: In Canada, there is a national level regulatory framework for methadone prescription. The Office of Controlled Substances, Health Canada, works with provincial/territorial governments and medical licensing bodies, among others, to facilitate increased access to methadone maintenance treatment. To prescribe 
methadone for the treatment of opioid dependence, physicians must be exempted under section 56 of the Controlled Drugs and Substances Act. As well, the support of the physician's licensing body is required. British Columbia, Saskatchewan, Ontario and Quebec have their own provincial guidelines for practitioners prescribing methadone in those provinces. For example, in the Vancouver Coastal Health Clinical, treatment guidelines for methadone maintenance do not require previous attempts at opioid abstinence for entry into methadone maintenance treatment. The guidelines note that the College of Physicians and Surgeons of British Columbia must keep record of anyone seeking admission to methadone maintenance treatment . Each Community Health Centre is required have a physician to prescribe methadone. Methadone maintenance treatment is initiated by a multidisciplinary health care team with ongoing assessment. Expedited admission to methadone maintenance treatment is available for pregnant women and those at high-risk for infectious diseases, such as HIV. Regular acceptance into methadone maintenance treatment is based on assessment for: DSM-IV requirements for opioid dependence; establishment of a treatment plan that outlines treatment objectives, methods, conditions and expectations; creation of a treatment agreement; complete medical history with appropriate laboratory evaluation; psychosocial evaluation; and voluntary consent. For other provinces, Health Canada has developed the guidelines entitled "The Use of Opioids in the Management of Opioid Dependence" [69]. These guidelines concur that the use of pharmacotherapies can reduce health risks and costs to the community. Support services addressing the psychological, social, and physical health issues in a drug user's life must be available in order that he or she may maximally benefit from treatment.

For detoxification, specific opioids may only be used orally. They are: methadone; codeine (for codeine dependence or where a shortacting opioid is required); pentazocine (for pentazocine dependence); propoxyphene (for propoxyphene dependence) and tincture of opium for use in the treatment of an opioid-dependent neonate. For methadone maintenance, a stable dose is provided, once daily, over a prolonged period for the treatment of individuals with a diagnosis of opioid dependence. Methadone dosing is individualized with the majority of patients being treated at a dose lower than $80 \mathrm{mg} /$ day. Doses of more than $100 \mathrm{mg} /$ day must be justified and the reasons clearly documented on the patient's file. To minimize methadone diversion, carry or take home privileges are limited. They are limited to a maximum period of four days or a maximum total dosage of $400 \mathrm{mg}$, whichever is lesser. No carry privileges, except for weekends, are granted to patients receiving more than $100 \mathrm{mg}$ of methadone per day appropriate dispensing facilities (such as pharmacies, hospitals, or treatment centers) are used for dispensing and for supervised administration of methadone. Methadone maintenance treatment may be delivered in a variety of different settings including: substance use treatment services/clinics (outpatient/inpatient); community-based health centers/clinics; private medical clinics; individual physicians' offices \& community pharmacies; hospital-based health clinics; HIV/ AIDS services/clinics; mental health agencies/clinics; and correctional facilities. When methadone maintenance therapy is initiated in a specialized multidisciplinary treatment center, the center must offer, at a minimum, the following services to opioid-dependent persons: initial medical, psychiatric and psychosocial assessment; ongoing psychosocial treatment (e.g. counseling on an individual, group or family basis) and aftercare; ongoing medical management; and provision for appropriate methadone dispensing and administration, and urine drug testing according to the guidelines. All treatment centers or acceptable alternatives must be approved by provincial medical licensing authorities. In Canada, the primary care physician/private practitioner plays an important role in methadone treatment. There is a changed treatment environment where the focus of methadone maintenance treatment has been altered from elimination of all opioid use to social reintegration, where abstinence is viewed as one of a range of options to mitigate the consequences of opioid abuse and dependence [70,71]. In this new environment, a cooperative and integrated system has been developed linking family physicians with the specialized centers in an attempt to mainstream methadone maintenance treatment, particularly into HIV primary care [72]. By providing addiction treatment training and education, along with a standardized clinical reference manual, in addition to linking primary care physicians to addiction treatment specialists in mentoring programs, methadone maintenance treatment has become an integral part of HIV primary care. The mentor program ensures continuing education, clinical support and quality control. For the primary care provider/private practitioner, their patient case load is important. The number of patients a private practitioner may treat with methadone maintenance depends on the professional and therapeutic involvement each patient will require. In addition, the private practitioner must have established a formal affiliation with a substance abuse treatment center, as defined above, to ensure a level of care that is consistent with the clinical management expectations outlined in the Health Canada guidelines [69]. Finally the necessary qualifications for a private practitioner undertaking the treatment of opioid dependency are to be determined by the provincial medical licensing authority.

\section{Buprenorphine}

Buprenorphine treatment for opioid dependence has been available in Canada since 2007 but has been underutilized due to a number of reasons, including limited access in some provinces, increased cost of the medication relative to methadone and possibly because of a lack of clinical guidelines [73]. Clinical guidelines from the Centre for Addiction and Mental Heath entitled "Clinical Practice Guideline Buprenorphine/Naloxone for Opioid Dependence" have recently been released and will be particularly useful for primary care/private practitioners in under-resourced and remote communities with limited access to specialized methadone treatment centers [73]. The guidelines provide clinical recommendations for the initiation, maintenance and discontinuation of buprenorphine/naloxone treatment for individuals who are opioid dependent. The guidelines are important since any physician in Canada can currently prescribe buprenorphine without any prior training; however, the College of Physicians and Surgeons of Ontario expect that all physicians who decide to use buprenorphine in the management of opioid dependence will have both addiction medicine training as well as training and education in the use of buprenorphine [74]. The College recommends, but does not require, a buprenorphine education course, such as, the course available from the Centre for Addiction and Mental Health. The College also recommends completion of at least a one-day clinical observership on the use of buprenorphine in a clinical practice, and ongoing continuing medical education in the treatment of opioid dependence.

Access to buprenorphine and coverage through the provincial medication insurance plans of the national healthcare system varies, possibly due to the higher cost of buprenorphine relative to methadone [75]. There is no coverage in British Columbia, Saskatchewan, Manitoba, Prince Edward Island, Newfoundland and Labrador; 
coverage is restricted to methadone prescribers in Alberta, New Brunswick and Nova Scotia. Coverage is provided in Ontario and Quebec if methadone treatment has failed or is not locally available, is not tolerated by the patient or is contraindicated.

Access to buprenorphine treatment and provider expertise is important in addressing the growing problem in Canada of prescription opioid abuse and dependence, especially in remote areas where access to methadone is limited [76]. An increasing number of patients with prescription opioid dependence have been noted in Canadian publically funded addiction treatment programs [77]. The growth in prescription opioid dependence will require a growth in treatment opportunities, and expansion of both methadone and buprenorphine treatment is important to address this need. Since buprenorphine can be prescribed by any physician in Canada, buprenorphine is a medication that can rapidly be deployed to address this need.

\section{Other pharmacotherapy paradigms}

In Canada, maintenance treatment with diacetylmorphine (i.e., heroin) for individuals with treatment-refractory opioid dependence is an option that remains controversial and often a politically charged subject [78]. The North American Opiate Medication Initiative (NAOMI) trial in Canada showed heroin-assisted maintenance of "refractory" opioid dependence to have better outcomes compared to methadone treatment in terms of retention in treatment and clinical response $[79,80]$. An important caveat is that all those in the trial had previously failed methadone treatment, and so those randomized to methadone were, in effect, randomized to a treatment previously found ineffective. Regardless, these data show the clinical effectiveness of heroin as a harm reduction option for patients who continually fail methadone maintenance treatment. Nevertheless, heroin maintenance is not without risks and the NAOMI trial reported increased rates of seizures and overdose in the heroin treatment arm and suggested heroin maintenance should be conducted in supervised medical settings. A recent Cochrane review of heroin-assisted maintenance alone or in combination with methadone treatment has validated heroin-maintenance as an important option for treatment refractory patients [81].

\section{Europe}

Opioid dependence epidemiology: European Union countries have a sizable opioid dependent adult population with an estimated of 94-400 persons per 100,000 in the 15-64 years of age group [82]. There are large variations in European countries response to opioid use in term of prevalence of use, treatment regulations, and legal consequences of use. However, it is clear that opioid use is the self-reported primary drug of abuse for the majority of individuals entering specialized treatment in Europe. Data from 2008 showed that $53 \%$ of patients in specialized treatment reported opioid use as primary illicit drug of abuse and $48 \%$ of all patients reported using heroin [83]. The range of treatment admissions for opioid dependence range in Europe from 10 to $90 \%$ (Bulgaria, Estonia and Slovenia) [83]. European Monitoring Centre for Drugs and Drug Addiction (EMCDDA) estimates the prevalence of problem opioid use in European countries also vary widely with approximately one to eight cases per 1,000 population aged 15-64 with the overall prevalence of problem drug use estimated to range from two to ten cases per 1,000 during 2003-08 [83]. Problem drug use was defined as "injecting drug use or long-duration/regular use of opioids, cocaine and/or amphetamines" [84].

Opioid dependence treatment: There is no central European agency that regulates opioid treatment in individual countries. Instead, each country issues its own set of regulations and treatment protocols and has initiated new MAT programs over the last 10 years in different time frames, as shown in Table 2. The treatment approach in Europe, however, is similar to what is being reported in North America. That is, for the treatment of opioid dependence, the use of opioid agonist maintenance treatment combined with psychosocial services is the most effective treatment paradigm for improving treatment retention, reducing illicit opioid use and mortality. The use of methadone maintenance treatment or buprenorphine maintenance treatment is documented as "beneficial" and the use of naltrexone for preventing relapse as "likely beneficial" using the GRADE system [85]. Methadone maintenance and buprenorphine maintenance treatment regulations, however, differ among the European countries with some countries allowing prescription of opioid agonists under less stringent conditions than in North America. In addition, the use of slow-release oral morphine as maintenance treatment is approved in some countries. As noted earlier, certain European countries (Belgium, Denmark, Germany, Netherlands, and United Kingdom) also allow the existence of programs delivering heroin (diacetylmorphine) under medical supervision for chronic heroin users who have failed methadone treatment (so called "refractory users") [86]. This approach has shown to be beneficial in improving physical and psychological outcomes, treatment retention, and mortality in refractory users but warrants careful monitoring [87].

Data presented below are based on the EMCDDA report on the legal framework of opioid agonist initiation, continuation, and dispensing in 25 of the 27 European Union countries as well as for Turkey and Norway [88]. These countries will be presently referred to as "EMCDDA countries". Of the European Union countries, there is no reported data for Malta and Sweden. For the EMCDDA countries, Turkey is the only country that does not offer opioid agonist maintenance treatment.

\section{Methadone}

The legal frameworks for the use of methadone for the treatment of opioid dependence vary depending on the country [86]. Initiation (induction) and/or maintenance can occur at specialized treatment centers in all EMCDDA countries providing methadone treatment with the exception of Denmark and Cyprus. Other options that are also available are: initiation (induction) and/or maintenance by specifically trained or accredited office-based physicians or general practitioners who practice medicine outside the specialized drug treatment centers (Belgium Flemish Community, Denmark, Germany, Ireland, Luxembourg, Netherlands, Austria, Portugal, Slovenia, and United Kingdom, Norway); initiation (induction) and/or maintenance by office-based medical doctors practicing outside specialized drug treatment centers (Belgium, Denmark, Germany, France, Italy, Netherlands, Romania, and United Kingdom); 3) initiation and/ or continuation by other providers such as initiation by medical nurses in the Netherlands and continuation by pharmacist and nurse independent prescribers in the United Kingdom. Dispensing occurs at any combination of specialized treatment centers, specialized and/or any medical doctor offices, pharmacies, and/or mobile outreach units depending on the country [88].

Buprenorphine: Aside from Turkey, Bulgaria, and Poland, all countries offer buprenorphine and/or buprenorphine/naloxone $\left(\right.$ Suboxone ${ }^{\circledR}$ ) [88]. In Spain, high dosage buprenorphine is not commercially available. Buprenorphine and/or buprenorphine/ 
naloxone can be initiated by medical doctors in specialized treatment centers in the majority of the countries (exceptions are Denmark, Cyprus, and Slovania) and depending on the country, other options are also available. Initiation and/or continuation by specifically trained or accredited office-based medical doctors or general practitioners practicing outside specialized drug treatment centers are available in Belgium Flemish Community, Denmark, Germany, France, Luxembourg, Netherlands, Austria, Portugal, Slovenia, United Kingdom, and Norway; initiation and/or continuation by office-based medical doctors practicing outside specialized drug treatment centers is available in Belgium French Community, Czech Republic, Denmark, France, Germany, Italy, Netherlands, Cyprus, Portugal, Romania, and United Kingdom. No country reported initiation by professionals other than medical doctors but continuation is allowed by pharmacists and nurse independent prescribers in the United Kingdom. Dispensing occurs at any combination of specialized treatment centers, specialized and/or any medical doctor offices, pharmacies, and/or mobile outreach units depending on the country. For the majority of the EMCDDA countries, legal frameworks are similar for both methadone and buprenorphine or buprenorphine/naloxone [88].

Although methadone and buprenorphine may both be available in a country, specific countries may have preferences on a specific treatment made available. In Spain, for example, methadone is preferred over buprenorphine, likely due to its lower cost. France, in contrast, favors buprenorphine, likely due to its improved safety profile (lower respiratory depression) compared to methadone.

Naltrexone: Naltrexone is a non-opioid, non-scheduled medication and does not require legal frameworks as opposed to opioid agonists. Oral naltrexone has proved ineffective for most individuals because of low treatment adherence. In an attempt to counteract this, implants and injectable forms have been engineered. Implants are usually inserted in the subcutaneous tissue of the lower abdominal wall and deliver naltrexone for variable duration, some up to one year $[89,90]$. Extended-release injectable naltrexone, Vivitrol $^{\circledR}$, is administered via intramuscular injection in the gluteal region and delivers naltrexone for about one month (see Table 1). Depot formulations have been approved at different rates in different countries [90]. Several studies, including randomized controlled trials, suggest that the use of depot naltrexone can lead to reductions in opioid use and retention in treatment compared to placebo [34].

Slow release morphine: Bulgaria, France, Italy, Luxemburg, Netherlands, Austria, Slovenia, and the United Kingdom allow treatment using slow release oral morphine (SROM) [91]. The use of

Methadone--Federally regulated through OTP; long-acting opioid receptor agonist for pharmacological therapy; can be used in detoxification or in long term (maintenance) treatment

Buprenorphine-office-based opioid treatment or OTPs; Federally regulated, long-acting opioid receptor partial agonist for pharmacological therapy; can be used in detoxification or in long term (maintenance) treatment

Naltrexone--office-based and substance abuse treatment programs; nonnarcotic opioid receptor antagonist for relapse prevention without abuse liability or reinforcing effects; used after detoxification from opioids to prevent relapse to opioid use

Vivitrol- extended release naltrexone; non-narcotic opioid receptor antagonist for relapse prevention without abuse liability or reinforcing effects; used after detoxification from opioids to prevent relapse to opioid use

Table 1: Pharmacotherapies Comprising Medication Assisted Treatment for Opioid Abuse and Dependence.
SROM for maintenance treatment, however, remains controversial and scarcely studied. A recent literature review of the available clinical trials on the use of SROM concluded that there was currently no definite evidence showing that SROM is an effective alternate to methadone for opioid maintenance treatment [91].

\section{Countries outside the european union}

Ukraine: Ukraine has an estimated 400,000 people who inject drugs and who are either infected or at-risk for HIV infection [92]. Ukraine has, therefore, implemented MAT as part of their national response to HIV/AIDS. A series of official policies and programs were developed and endorsed, increasing the capacity of the health care system to expand access of people living with HIV/AIDS to diagnostic, treatment, family planning, drug treatment and reproductive health services. Buprenorphine was the first MAT implemented, with methadone following several years later [93]. In April 2007, the 'Road Map on Scaling-up Towards Universal Access to HIV/AIDS Prevention, Treatment, Care and Support in Ukraine by 2010' was endorsed by the Government of Ukraine to guide the process of scaling-up the coverage of HIV/AIDS services [94]. A Presidential decree established that the Committee for Drug Control would immediately support the importation of methadone, which was needed to scale-up MAT. In late 2007, the Government of Ukraine developed a new AIDS Concept and Program for the period 2009-2013. MAT, including both methadone and buprenorphine, are now being delivered by nongovernment organizations and the Ministry of Health in all regions of Ukraine. To date, approximately 6,500 individuals are receiving MAT in 2011, with the majority $(5,713)$ of patients receiving methadone maintenance treatment. The latest target set by the Ukrainian Government to scaleup methadone maintenance treatment by 2014 was set at 20,000 people who inject drugs and who are opioid dependent. Despite this goal, however, changes in treatment policy and increased policing with the resulting fears have discouraged methadone clinics from substantially increasing patient volume [95].

Belarus: In Belarus, it is estimated that there are 50,000 people who inject drugs and injection drug use is closely linked to HIV infection [96]. Methadone maintenance treatment was introduced into Belarus in 2008 through funding from the Global Fund To Fight AIDS, Tuberculosis and Malaria [97]. The initial pilot clinic served 40 individuals and was located in the capital Minsk. The methadone maintenance program has expanded to a network of clinics across the country serving over 450 patients. The treatment programs had initially strict criteria to enter treatment. To receive methadone maintenance treatment a drug user had to be able to either demonstrate several unsuccessful attempts to give up heroin injection, to have been living with HIV, or have another co-morbid condition such as hepatitis $\mathrm{C}$ infection. The successful expansion of methadone maintenance treatment has resulted in a loosing of these criteria to allow any person who expresses a desire to stop injecting heroin to have access to methadone treatment.

\section{Russian federation}

The Russian Federation has a serious injection drug-use epidemic coupled with an HIV/AIDS epidemic. The Joint United Nations Program on HIV/AIDS (UNAIDS) estimates that in Russia, that there are up to 2 million injecting drug users with 60-70\% having HIV-related illnesses [98]. It is also estimated that up to two-thirds of new HIV cases in Russia are linked to injected drug use, and an estimated one million people are living with HIV/AIDS. Methadone is illegal in the 
Russian Federation. While buprenorphine is a registered medication in the Russian Federation, it is illegal to prescribe or dispense a narcotic medication to an injection drug user. Thus, naltrexone is currently the only pharmacotherapy available for treatment of the heroin epidemic in the Russian Federation [32]. Oral naltrexone is widely available in Narcology clinics throughout the Russian Federation on a feefor-service basis. But its high cost does not allow for substantial use, even though studies have shown that oral naltrexone is effective in preventing relapse to heroin use where people who inject drugs have strong support groups to promote medication adherence [32]. Recently in 2011, Vivitrol ${ }^{\circledR}$ has been approved for use in the Russian Federation as a medication to prevent relapse to heroin use. Initial reports have indicated that some Oblasts have purchased large quantities of Vivitrol ${ }^{\mathbb{R}}$ to enhance access to the medication for people who inject drugs after detoxification. In addition, The President's Emergency Plan for AIDS Relief (PEPFAR) has approved a collaborative project to evaluate the use of Vivitrol ${ }^{\circledR}$ in an AIDS treatment setting in St. Petersburg to reduce HIV transmission among people who inject drugs.

\section{Asia-pacific region}

Treatment epidemiology: Heroin has had a presence in the Asian-Pacific region for a long time and countries and territories in this region have been implementing MAT since as early as 1972 . Implementations have also started as recently as 2010 . The countries implementing MAT in this region are: China in 2004; Cambodia in 2010; Hong Kong in 1972; Indonesia in 2006; Malaysia in 2006; Mynamar in 2006; India in 1986; Thailand in 1995; and Vietnam in 2008. The difference in initiating MAT is not based when heroin entered a country, but reflects when a specific country or territory was motivated to begin MAT. Vietnam, for example, has had heroin for decades before implementation of methadone maintenance treatment, whereas, Hong Kong quickly addressed their heroin problem with methadone maintenance treatment in $1972[99,100]$. The movement to implement MAT in this region, is not a health policy shift to viewing opioid dependence as a medical disease requiring medical treatment, but a public health response to HIV among people who inject drugs.

The HIV epidemic in this region is concentrated in three particular populations: people who inject drugs, commercial sex workers and men who have sex with men. The largest risk group for HIV infection in this region is people who inject drugs. Estimates of this population range from 2,000 to 2,350,000 and HIV prevalence rates range from $15 \%$ to $60 \%[14,101]$. The use of MAT for HIV prevention is clearly a medical means to address the issue of HIV infection in a disenfranchised population in a region where detention and control of people who inject drugs has been the normal police response. This new medicalbased approach is an evidence-based, client-centered approach to addressing the nexus between heroin dependence and HIV infection [102-103].

The treatment of heroin dependence in the region utilizes methadone and buprenorphine. Methadone is the predominant treatment in the region, with Indonesia, Taiwan and India utilizing buprenorphine. Recently China, Vietnam and Cambodia implemented methadone maintenance treatment as a community-based program to address the heroin addiction problem in their respective countries.

\section{Peoples republic of china}

Methadone: China has a current policy that supports methadone treatment for opioid dependence as a national approach to the HIV/ AIDS epidemic [104]. The national approach to HIV/AIDS is to develop pragmatic solutions to the changing epidemic based on sound scientific information. This national approach evolved over time through the initial phases of the HIV epidemic which can be defined as: 1985-1988 the period HIV entered the Chinese society; 1989-1994 rapid expansion of the epidemic with HIV transmission among groups at highest risk, such as people who inject drugs; and 1995-2002 further spread of HIV/ AIDS nationally. China's initial response was via a police crackdown on drug use. Incarceration, rehabilitation units with labor or compulsory detoxification were used [104]. However, this strategy did not stop the spread of HIV. In 2001, China developed an initial five-year action plan for the containment and control of HIV. The language of the plan did not condone the "social evil' of drug use but did introduce the concept of community-clinic-based treatment for drug users as HIV prevention. This was a policy milestone in the support of methadone maintenance treatment. The second five-year plan (2006-2010) was developed in a public health supportive environment with specific and ambitious targets for prevention programs for marginalized populations. The targets for people who inject drugs were the establishment of methadone maintenance treatment clinics in counties and cities with more than 500 drug users registered with the Public Security Bureau and to have greater than $70 \%$ of opioid dependent individuals receive methadone maintenance services. These targets greatly facilitated the scale-up of methadone treatment with the number of opioid dependent persons receiving methadone treatment rising from 8,116 in 2005 to 241,975 in 2009 [105]. This scale-up of MAT in China resulted in injection drug use falling from the primary mode of HIV transmission to a secondary mode even though the number of registered drug users increased from 70,000 in 1990 to 1.16 million in 2005 [106]. Heroin dependent individuals receiving methadone maintenance services in the Department of Health's voluntary detoxification institutions were characterized as individuals who initiated opioid use by smoking opium, were younger than 35 years of age and married with a high school education [107].

Buprenorphine: Buprenorphine/naloxone is not licensed for use in China. However, a NIH HIV Prevention Trial Network (HPTN) 058 randomized trial comparing risk reduction counseling combined with either short-term or long-term MAT with buprenorphine/naloxone was initiated to prevent HIV infection and death among opioiddependent injectors. An initial report of the study [108] showed that buprenorphine/naloxone was well tolerated in this group of patients.

\section{Taiwan}

Methadone: Taiwan has had success in addressing the spread of HIV infection among its estimated 60,000 injection drug users by an aggressive implementation and scale-up of methadone treatment programs. Methadone maintenance treatment was introduced in 2005 as an experimental pilot program and quickly grew to 60 treatment programs across the country serving 15,000 patients. To date, 77 local hospitals cooperate with the Taiwan Centers for Disease Control in offering methadone maintenance treatment to people who inject drugs, with the Department of Health and Department of Justice offering financial subsidies for the programs. Recently, the Department of Health, in collaboration with the Department of Justice, introduced methadone maintenance treatment in prisons in central and southern Taiwan in an effort to reduce recidivism among drug users and stem the spread of AIDS [110]. Recidivism to drug use was estimated at $90 \%$ post-prison release with people who inject drugs having a HIV infection prevalence of $33 \%$. Local injection drug users are in and out of prisons 
repeatedly, with little treatment options for opioid dependence outside of prison in this region.

Buprenorphine: Buprenorphine is not widely utilized in Taiwan, however, a multicenter trial of suboxone ${ }^{\circledR}$ was recently completed. This trial sponsored by Reckitt Benckiser Pharmaceuticals, Incorporated was a randomized open label trial of suboxone ${ }^{\circledR}$ for the treatment of opioid dependence in 120 patients [111]. Eight sites were selected including two mental hospitals, one psychiatric center, three general hospitals, and a university affiliated teaching hospital. This trial will promote the implementation of buprenorphine treatment for opioid dependence in Taiwan.

\section{Peoples republic of vietnam}

Vietnam has implemented and scaled-up methadone treatment as part of the national HIV prevention, care and treatment plan in collaboration with the PEPFAR program [112]. The Government of Vietnam estimates there are 150,000 drug users in Vietnam or approximately $0.5 \%$ of the male population aged 15 to 45 . Approximately $80 \%$ of drug users are thought to be heroin injectors. In December 2007, the Minister of Health issued the Decision No 5073/ Q\$-BYT and Decision No 5076/ Q\$-BYT on approval of the program "Pilot Implementation of Methadone Substitution Treatment Program in Hai Phong and HCM (Ho Chi Minh) City" and "Guidelines of Methadone Substitution Treatment and Implementing Guidelines". With these orders, the Government of Vietnam officially sanctioned MAT as an HIV prevention intervention [112]. At the local level, in pilot clinic districts, a Steering Board was set-up that was led by People's Committee Vice Chairperson whose purpose was to screen applicants for admission to methadone maintenance treatment.

With staff training, the initial patients received methadone treatment in early 2008. An evaluation of the pilot program detailed that no severe side effects were reported among the patients; no symptoms of overdose were detected among the patients receiving treatment; no new cases of HIV, hepatitis B or C were detected; the treatment retention at 9 months was $96.5 \%$ and there were 3 deaths $(0.3 \%)$ due to AIDS. The average methadone maintenance dose at 9 months was 109 $\mathrm{mg} /$ day for patients not receiving antiretroviral medication for HIV infection and $187 \mathrm{mg} /$ day for patients receiving either antiretroviral treatment or tuberculosis. The higher doses were required due to drug -drug interactions with methadone, a medical management complication for opioid dependent patients needing treatment for cooccurring infectious diseases [100]. In addition, 2 individuals $(0.4 \%)$ reported sharing needle/syringes in the first 6 months of methadone treatment but none thereafter; patient self-report of depression reduced from $80 \%$ at baseline to $5 \%$ after 9 months of methadone treatment; the reduction in drug use was $85 \%$, with improvements in health, emotional, and family and community [112].

The evaluation of the initial pilot project revealed a highly effective HIV prevention intervention and treatment for opioid dependence. With the successful pilot treatment of 1,700 patients, national scaleup of methadone treatment has begun to include the expansion of methadone treatment into seven new cities and provinces. The Government of Vietnam is planning to further scale-up methadone treatment nationwide with the target of 80,000 drug users accessing methadone treatment by 2015 [113].

Cambodia: Cambodia has also implemented methadone treatment as part of the national HIV/AIDS prevention, care and treatment plan in collaboration with the PEPFAR program and the World Health
Organization (WHO) [114]. Cambodia has an estimated 3,000 injection drug users with approximately 750 opioid dependent individuals infected with HIV. The first methadone treatment program opened in Phnom Penh in September 2010 by WHO and is administered by the Ministry of Health. Sixty patients have been initially enrolled in methadone treatment and plans were to reach 100 patients within a year. By mid-July 2011, 107 patients had been enrolled in the methadone treatment program with the characteristics: $20 \%$ were female; $14 \%$ dropped out of methadone treatment; three patient reenrolled; three patients died (HIV, hepatitis B, and one unknown cause of death); a mean dose for methadone maintenance - $82.23 \mathrm{mg} /$ day with a $95 \%$ medication adherence rate $[115,116]$.

\section{Australia}

In Australia, both methadone and buprenorphine are available in specialized clinics or through general practitioners with approximately 36,000 individuals receiving either methadone or buprenorphine treatment [14].

Methadone: Methadone became available in Australia in 1970 and its use as a treatment option for opioid dependence fell in and out of favor up until 1985 when methadone maintenance treatment became a major health intervention in limiting the transmission of HIV [117]. Over $85 \%$ of methadone maintenance treatment patients are treated by general practitioners and receive their methadone at community pharmacies [118]. The treatment system is publicly funded and integrated through links to specialized clinics that offer training and continuing education for general practitioners who provide methadone. These specialized clinics also serve as a back-up support in the treatment of complex cases. This delivery model provides positive treatment outcomes in the reduction or termination of illicit heroin use, and increased employment [118].

In Australia, methadone treatment is also provided in the prison system. For example, the New South Wales Prison Methadone Program provides prison-based methadone maintenance treatment for incarcerated injecting drug users dependent on opioids [119]. The goals of the prison-based methadone maintenance treatment program are to reduce recidivism, prevent the spread of HIV and hepatitis in prison, and encourage the continuation of treatment in the community following an inmate's release from prison. The program initially started as a prerelease treatment program but quickly scaled-up to a full maintenance treatment Australia's National Methadone Guidelines provide four categories where methadone maintenance treatment is appropriate for prisoners: 1) withdrawal; 2) continuation of treatment for those on methadone before imprisonment; 3) commencement of treatment for those who are heroin dependent on prison entry or who have used heroin in prison in a harmful way, including those who are HIV positive; and 4) the reduction of intravenous opioid use upon release [120].

Buprenorphine: Buprenorphine treatment for opioid dependence has been available since 2000. A National Buprenorphine Policy and National Clinical Guidelines and Procedures for the Use of Buprenorphine in the Treatment of Heroin Dependence was developed under the auspices of the Intergovernmental Committee on Drugs [121]. These policies and guidelines facilitated the introduction of buprenorphine for widespread use, with a focus on safe utilization. The availability of buprenorphine for treatment of opioid dependence is limited by the number of general practitioners willing to "opt-in" to prescribing buprenorphine [122]. This barrier to access to treatment is 
notable, since a recent study reported only 55 of approximately 2,000 general practitioners in South Australia were prescribers of opioid agonist medications. [122].

Malaysia: Records mention drug use as far back as the 8th century in Malaysia. Serious national efforts to address drug use occurred in the early 1980's when the estimated number of individuals addicted to drugs rose to roughly 100,000 and the Prime Minister declared drugs as the nation's number one enemy [123]. The Drug Dependents Treatment and Rehabilitation Act passed in 1983 allowed for compulsory detainment of drug users for up to two years in government run rehabilitation centers called "Pusat Serentis" [123]. In the centers, drug users were detoxified 'cold turkey' without pharmacotherapy. As estimates for drug users in Malaysia reached upwards of 500,000, methadone maintenance treatment for opioid dependence was initiated in Malaysia in 2005 as a harm reduction program to address HIV transmission. This pilot project was initiated in psychiatric hospital clinics and in primary care [124]. The success of the program resulted in the scaling-up of the program in 2008 to reach injection drug users in prisons and the Pusat Serentis centers. Expansion of MAT has also occurred at the ar-Rahman Mosque in Kuala Lumpur where free methadone maintenance treatment is provided [125]. This novel MAT treatment program is the first reported methadone treatment program where services are provided in a Mosque. The expansion of services has resulted in an estimated 7,000 individuals currently receiving treatment [14]. Research studies of MAT in Malaysia have compared naltrexone treatment to buprenorphine maintenance treatment in a randomized controlled trial and found that buprenorphine was superior in treatment retention to oral naltrexone [126].

Myanmar: A substantial barrier for people who inject drugs to receive treatment for opioid dependence is the government requirement to register as a drug user [127]. The Narcotics Drug and Psychotropic Substance Law of 1993 required punitive actions for registered drug users, not medically-based treatment [127] . However, the United Nations Office on Drugs and Crime (UNODC) in collaboration with the Government of Myanmar opened the first methadone maintenance treatment programs in 2006 as HIV prevention programs in Yangon, Mandalay, Lashio and Myitykina [128]. Additional treatment programs have opened in Muse and Tachileik. It is estimated that over 500 people who inject drugs are receiving methadone treatment in these clinics [14].

Thailand: In Thailand, opium has been used in ritual, social and medical contexts for centuries. However, change in opioid production has resulted in changes in consumption, with an increase in heroin smoking and injection [129]. Both methadone and buprenorphine treatment are available with approximately 5,000 individuals receiving treatment services [14]. A WHO collaborative study, reported in 2008, showed the need for the use of methadone as an HIV prevention intervention [130]. The opioid dependent participants in the study had a HIV prevalence rate of $52 \%$. Individuals treated with methadone maintenance treatment in this study showed excellent clinical outcomes. Thus, the methadone treatment programs initiated throughout Thailand have as a goal to limit the transmission of HIV [129].

India and south asia: It is estimated that there are between 400,000 and 750,000 people who inject drugs in the region that encompasses India, Afghanistan, Bangladesh, Bhutan, Maldives, Nepal, Pakistan and Sri Lanka Of these individuals, it is estimated that between 35,000 and 135,000 are HIV infected [131]. People who inject drugs in this region are at high-risk for HIV infection because they are concentrated in areas of high HIV prevalence [132]. Thus, there is and need for MAT services in South Asia as a HIV prevention intervention. While treatment for opioid dependence is largely abstinence-based, countries where methadone is available are Afghanistan, Bangladesh, Maldives, Nepal and Sri Lanka. Most treatment efforts are small pilot treatment programs. India has recently introduced both buprenorphine and buprenorphine/naloxone utilizing standardized protocols and supervision to minimize diversion of the medication [133,134]. Nepal has experienced a unique inject drug use epidemic with individuals injecting a liquid formulation of buprenorphine. Currently both buprenorphine and methadone are available with fewer than 500 individuals estimated to be receiving treatment with either medication [14].

In Iran, in 2001 the government estimated that, based on arrest records, there are between 1.3 to 2 million opiate dependent drug users and an estimated 140,000-200,000 injectors of opiates [135]. In 2008, it is estimated that 108,000 people were receiving MAT [14].

Central asia: In the Central Asian Republics, Kazakhstan, Kyrgyzstan and Tajekistan have initiated pilot methadone maintenance treatment programs. As pilot treatment programs, access to and coverage of people who inject drugs is limited given the injection drug use epidemic in those countries. Kazakhstan, for example, has an estimated 120,000 people who inject drugs with approximately 300 individuals receiving methadone maintenance treatment [14]. Kyrgyzstan, on the other hand, has an estimated 20,000 people who inject drugs with under 2000 receiving methadone maintenance treatment. Tajikistan has an estimated 15,000 people who inject drugs with approximately 300 receiving MAT. Ongoing international efforts continue to be undertaken to expand these methadone programs and scale-up MAT in the Central Asian Republics to address the larger injection drug use epidemic.

In Uzbekistan, there is an estimated 80,000 people who inject drugs. In 2009, the Government of Uzbekistan closed their pilot buprenorphine and methadone treatment programs [136]. The Uzbekistan government cited as its rationale for closure that the pilot had not demonstrated effectiveness and so there was no need to continue the program. The 200 patients receiving treatment were withdrawn from MAT.

\section{Africa}

East africa: The World Drug Report [2] details the trafficking of illicit opioids from South Asia to the East Coast of Africa. Thus, Somalia, Ethiopia, Kenya, North Sudan, South Sudan, Uganda, Tanzania, Mozambique, Zambia, Zimbabwe and South Africa are at high-risk for developing opioid injection drug abuse epidemics. This development would only compound their current epidemic of HIV infection, since most countries have limited capacity and expertise to address an outbreak of injection drug abuse and opioid dependence. In Uganda, Mozambique, Zambia and Zimbabwe stories can be heard of people who inject opioids, but there is yet to be a public health response. So MAT is not available for these individuals. However, efforts are being made in the implementation and scale-up of MAT in Tanzania, Kenya and South Africa as currently noted.

Tanzania: Over the last decade in Dar es Salaam, injection drug use, primarily of heroin, has threatened to reverse a declining HIV epidemic [137,138]. An estimated 50,000 drug users in Dar es Salaam inject heroin, of which $42 \%$ are estimated to be HIV infected. This compares to $9.3 \%$ overall HIV prevalence estimated for Dar es Salaam 
among people 15-49 years of age. There is also an additional 50,000 people who inject drugs outside of Dar es Salaam in other parts of Tanzania. In response to these data, methadone maintenance treatment was established in Dar es Salaam. This collaborative effort among the Drug Control Commission, the Muhimbili University of Health and Allied Sciences and PEPFAR represents an important achievement in providing evidenced based services to people who inject drugs in Africa. The first pilot methadone treatment program began accepting patients in 2011 with a goal of 200 patients. That goal was achieved in the first six months of the program. Retention in treatment has remained high and a formal evaluation will be conducted after the first year of operation is completed.

Kenya: Methadone treatment is currently only available in Kenya in the private sector but plans are underway to open two government supported methadone treatment programs in hospitals in the eastern part of the country. Currently, the private sector methadone treatment data for Kenya is unavailable. Thus, the actual number of individuals in treatment, the cost of treatment, retention in treatment, and overall changes in HIV risk behaviors remain unknown.

South africa: South Africa has buprenorphine treatment available in a private treatment setting. It is estimated that as many as 2,000 individuals may be receiving buprenorphine treatment through private practitioners on a fee-for-service basis. In addition, methadone treatment is available in a private practice setting as of 2011. A very small number of individuals (less than 50) are receiving methadone treatment. However, there are no national treatment guidelines available for these practitioners.

Mauritius: Treatment for injection drug use has existed in Mauritius for over 10 years. Heroin availability goes back to the 1980 's. In addition to heroin injection, the injection of buprenorphine has become popular and, is likely the result of the long colonial history between Mauritius and France. In 2006, a methadone maintenance treatment program was launched. A unique aspect of the Mauritius program is that patients are initially placed in an inpatient clinical environment for 14 days to initiate methadone. After 14 days, the patients are discharged to outpatient methadone maintenance treatment where treatment continues. Buprenorphine is not available; however, discussions are under way regarding the possible introduction of the medication to allow for greater patient choice.

\begin{tabular}{|c|c|}
\hline $\begin{array}{l}\text { Pharmacotherapy } \\
\text { Initiated }\end{array}$ & Country (year) \\
\hline Buprenorphine & $\begin{array}{l}\text { United States (2000), Canada (2007), Belgium (2003), } \\
\text { Bulgaria (2008), Czech Republic (2000), Denmark } \\
\text { (2008), Germany (2000), Greece (2002), Spain (2009), } \\
\text { Latvia(2005), Lithuania (2002), Hungary (2007), Malta } \\
\text { (2006), Portugal (2004), Romania (2007), Slovenia (2004), } \\
\text { Norway (2001), (Ukraine 2004), Australia (2000), India } \\
\text { (2007) }\end{array}$ \\
\hline Methadone & $\begin{array}{l}\text { Mexico (2001), Estonia (2001)-maintenance, Malta- (2005)- } \\
\text { take home methadone, Ukraine (2006), Belarus (2008), } \\
\text { China (2004), Cambodia (2010), Indonesia(2006), } \\
\text { Malaysia (2006), Mynamar (2006), Vietnam(2008), } \\
\text { Tanzania (2011), Maruitius (2006), Afghanistan(2011) }\end{array}$ \\
\hline Vivitrol $\circledast$ & United States(2010), Russian Federation (2011) \\
\hline Substitol & Bulgaria (2006), Slovenia (2005) \\
\hline
\end{tabular}

\begin{tabular}{|l|l|}
\hline Country & Pharmacotherapy Expanded (Scale-up) \\
\hline United States & Methadone \\
\hline Bulgaria & Methadone \\
\hline Ireland & Methadone \\
\hline Greece & Methadone \\
\hline Italy & Buprenorphine \\
\hline Latvia & Methadone \\
\hline Austria & Substitol \\
\hline Poland & methadone \\
\hline
\end{tabular}

\# Pharmacotherapies initially implemented prior to the year 2000 and scaled-up after the year 2000

Table 3: Summary of the Expanded Utilization Since the Year 2000 of Medication Assisted Treatment for the Treatment of Opioid Abuse and Dependence ${ }^{\#}$.

Barriers to the Implementation and Scale-up of MAT: There are common challenges to the implementation and scale-up of MAT that has occurred globally over the last 10 years (Tables 2 and 3), in particularly where the favored approach to drug users is detention and control. The common challenges to the implementation and expansion of effective, high quality MAT treatment programs are: a need to increase country ownership; domestic technical ability and financial funding of MAT; a lack of capacity of human resources, staff skills and trained mentors; a need to incorporate MAT into medical and counselling programs within the existing formal and informal training and education programs; a need to incorporate MAT into law enforcement education programs; a need to integrate MAT into the existing network of health services, e.g. HIV/AIDS, TB, STI's, Sexual \& Reproductive Health (SRH), Mental Health, Maternal \& Child Health $(\mathrm{MCH})$, primary healthcare; the need to reduce stigma and discrimination of people who need MAT and other health services to increase the demand for, and access to, quality services; and to meet treatment demand as well as the UNODC/WHO/UNAIDS recommendation to reach $40 \%$ of people who inject drugs with MAT services, national MAT programs need to develop a spectrum of services including low threshold MAT programs to maximize the access to prevention, care and treatment for people who inject drugs.

\section{Summary and Conclusion}

The World Drug Report [2] estimates the total number of people using illicit drugs at approximately 250 million people. This is roughly equivalent to 4 per cent of the global population aged 15 to 64 . From those individuals, it is estimated that as many as 38 million people are drug dependent. However, only approximately 5 million people receive evidence-based drug dependence treatment and care. MAT is an evidence-based treatment for opioid dependence. While there have been a substantial number of MAT programs initiated over the last ten years, much more needs to be done particularly with reducing barriers to these essential medical programs in order to address the global epidemic of opioid abuse and dependence.

\section{References}

1. Jan SA (2010) Introduction: landscape of opioid dependence. J Manag Care Pharm 16: S4-8.

2. United Nations Office of Drugs Control (UNODC). World Drug Report 2010 United Nations Publications, New York, 2010 pp 42-51.

3. Carinci AJ, Mao J (2010) Pain and opioid addiction: what is the connection? Curr Pain Headache Rep 14: 17-21.

4. Shuster S (2011) The Curse of the Crocodile: Russia's Deadly Designer Drug Time (World) June20. 
Citation: Kresina TF, Bruce RD, Pirard S, Mulvey K, Huesca RS, et al. (2012) International Expansion of the Use of Pharmacotherapies for the Treatment of Opioid Dependence. Clin Exp Pharmacol S5. doi:10.4172/2161-1459.S5-001

Page 12 of 14

5. American Psychiatric Association (1994) Diagnostic and Statistical Manual of Mental Disorders, Fourth Edition. American Psychiatric Association Washington DC 176-183.

6. Stockman JK, Strathdee SA (2010) HIV among people who use drugs: a global perspective of populations at risk. J Acquir Immune Defic Syndr 55: S17-22.

7. Friedland G (2010) Infectious disease comorbidities adversely affecting substance users with HIV: hepatitis $\mathrm{C}$ and tuberculosis. J Acquir Immune Defic Syndr 55: S37-42.

8. Substance Abuse and Mental Health Services Administration, SAMHSA. Medication-assisted treatment for opioid addiction in Opioid Treatment Programs. Treatment Improvement Protocol (TIP) 43. Department of Health and Human Services Publication No. 05-4048. Rockville Maryland 2005.

9. Metzger DS, Woody GE, O'Brien CP (2010) Drug treatment as HIV prevention: a research update. J Acquir Immune Defic Syndr 55: S32-36.

10. International Narcotics Control Board. Report of the International Narcotics Control Board for 2010. United Nations Publication, New York 2011. Sales No. E.11.XI.1, ISBN 978-92-1-148258.

11. International Narcotics Control Board. Report of the International Narcotics Control Board on the Availability of Controlled Drugs: Ensuring Adequate Access for Medical and Scientific Purposes. United Nations Publication, New York 2011. Sales No. E.11.XI.7, ISBN 978-92-1-148260-7.

12. Kreek MJ, Borg L, Ducat E, Ray B (2010) Pharmacotherapy in the treatment of addiction: methadone. J Addict Dis. 29: 200-216

13. Banta-Green CJ, Maynard C, Koepsell TD, Wells EA, Donovan DM (2009) Retention in methadone maintenance drug treatment for prescription-type opioid primary users compared to heroin users. Addiction 104: 775-783.

14. Mathers BM, Degenhardt L, Ali H, Wiessing L, Hickman M, et al. (2010) HIV prevention, treatment, and care services for people who inject drugs: a systematic review of global, regional, and national coverage. Lancet 375: 10141028.

15. Connock M, Juarez-Garcia A, Jowett S, Liu Z, Taylor RJ, et al. (2007) Methadone and buprenorphine for the management of opioid dependence: a systematic review and economic evaluation. Health Technol Assess 11: 1-171.

16. Skinner ML, Haggerty KP, Fleming CB, Catalano RF, Gainey RR (2011) Opiate-addicted parents in methadone treatment: long-term recovery, health, and family relationships. J Addict Dis 30: 17-26.

17. Bruce RD (2010) Methadone as HIV prevention: high volume methadone sites to decrease HIV incidence rates in resource limited settings. Int J Drug Policy 21: $122-124$

18. Payte JT , Zweben JE (1998) Opioid maintenance therapies. In: Principles of Addiction Medicine. 2nd ed. Chevy Chase, MD: American Society of Addiction Medicine, Inc publisher pp 557-570.

19. Dole VP, Nyswander M (1965) A Medical Treatment for Diacetylmorphine (Heroin) Addiction. A Clinical Trial with Methadone Hydrochloride. JAMA193: 646-50.

20. NIH (National Institutes of Health) Effective Medical Treatment of Opiate Addiction. NIH Consensus Statement. Bethesda, MD: National Institutes of Health. 1997. no $15 \mathrm{pp}: 1-38$.

21. Kerr T, Wodak A, Elliott R, Montaner JS, Wood E (2004) Opioid substitution and HIVIAIDS treatment and prevention. Lancet 364: 1918-1919.

22. Doran CM, Shanahan M, Mattick R, Ali R, White J, et al. (2003) Buprenorphine versus methadone maintenance: a cost-effectiveness analysis. Drug Alcohol Depend 71: 295-302.

23. Barnett PG, Zaric GS, Brandeau ML (2001) The cost-effectiveness of buprenorphine maintenance therapy for opiate addiction in the United States. Addiction 96: 1267-78.

24. Mendelson J, Flower K, Pletcher MJ, Galloway GP (2008) Addiction to prescription opioids: characteristics of the emerging epidemic and treatment with buprenorphine. Exp Clin Psychopharmacol 16: 435-441.

25. Ling W, Smith D (2002) Buprenorphine: blending practice and research. J Subst Abuse Treat 23: 87-92.

26. Walsh SL, Preston KL, Stitzer ML, Cone EJ, Bigelow GE (1994) Clinical pharmacology of buprenorphine: ceiling effects at high doses. Clin Pharmacol Ther 55: 569-580.
27. Schuh KJ, Walsh SL, Bigelow GE, Preston KL, Stitzer ML (1996) Buprenorphine, morphine and naloxone effects during ascending morphine maintenance in humans. J Pharmacol Exp Ther 278: 836-846.

28. Yokell MA, Zaller ND, Green TC, Rich JD (2011) Buprenorphine and buprenorphine/naloxone diversion, misuse, and illicit use: an international review. Curr Drug Abuse Rev 4: 28-41.

29. O'Connor PG (2010) Advances in the treatment of opioid dependence: continued progress and ongoing challenges. JAMA 304: 1612-1614.

30. George S, Ekhtiari H (2010) Naltrexone in the treatment of opioid dependence. $\mathrm{Br} \mathrm{J}$ Hosp Med (Lond) 71: 568-570.

31. Greenstein RA, Evans BD, McLellan AT, O’Brien CP (1983) Predictors of favorable outcome following naltrexone treatment. Drug Alcohol Depend 12 : 173-180.

32. Krupitsky E, Zvartau E, Woody G (2010) Use of naltrexone to treat opioid addiction in a country in which methadone and buprenorphine are not available. Curr Psychiatry Rep 12: 448-453.

33. Minozzi S, Amato L, Vecchi S, Davoli M, Kirchmayer U, et al. (2011) Ora naltrexone maintenance treatment for opioid dependence. Cochrane Database Syst Rev: CD001333.

34. Krupitsky E, Nunes EV, Ling W, Illeperuma A, Gastfriend DR, et al. (2011) Injectable extended-release naltrexone for opioid dependence: a double-blind placebo-controlled, multicentre randomised trial. Lancet 377: 1506-1513.

35. Olsen L, Christophersen AS, Frogopsahl G, Waal H, Mørland J (2004) Plasma concentrations during naltrexone implant treatment of opiate-dependent patients. Br J Clin Pharmacol 58: 219-222.

36. Ramenskaya G, Shikh E, Arzamastsev A, Kukes V (2005) Molecular biological problems of drug design and mechanism of drug action. Pharmacokinetic study of the new domestic hypodermic form of naltrexone: prodetoxon depot tablets. Pharm Chem J 39: 1-3.

37. Woody GE, Metzger DS (2011) Injectable extended-release naltrexone for opioid dependence. Lancet 378: 664-665.

38. Ngo HT, Arnold-Reed DE, Hansson RC, Tait RJ, Hulse GK (2008) Blood naltrexone levels over time following naltrexone implant. Prog Neuropsychopharmacol Biol Psychiatry 32: 23-28.

39. Waal H, Frogopsahl G, Olsen L, Christophersen AS, MÃ rland J (2006) Naltrexone implants -- duration, tolerability and clinical usefulness. A pilo study. Eur Addict Res 12: 138-144.

40. Alper KR, Lotsof HS, Frenken GM, Luciano DJ, Bastiaans J (2000) Ibogaine in acute opioid withdrawal. An open label case series. Ann N Y Acad Sci 909: 257-259.

41. Johnson EE, Chieng B, Napier I, Connor M (2006) Decreased mu-opioid receptor signalling and a reduction in calcium current density in sensory neurons from chronically morphine-treated mice. Br J Pharmacol 148: 947-955.

42. Tahsili-Fahadan P, Malcolm R, Aston-Jones G (2010) Modafinil: an anti-relapse medication. Neuropsychopharmacology 35: 343-344.

43. Ockert DM, Volpicelli JR, Baier AR Jr, Coons EE, Fingesten A (2011) A nonopioid procedure for outpatient opioid detoxification. J Addict Med 5: 110114.

44. Jegu J, Gallini A, Soler P, Montastruc JL, Lapeyre-Mestre M (2011) Slowrelease oral morphine for opioid maintenance treatment: a systematic review. $\mathrm{Br} J$ Clin Pharmacol 71: 832-843.

45. Oviedo-Joekes E, Guh D, Brissette S, Marsh DC, Nosyk B, et al. (2010) Doubleblind injectable hydromorphone versus diacetylmorphine for the treatment of opioid dependence: a pilot study. J Subst Abuse Treat 38: 408-411.

46. Fischer B, Rehm J, Kirst M, Casas M, Hall W, et al. (2002) Heroin-assisted treatment as a response to the public health problem of opiate dependence. Eur J Public Health 12: 228-234.

47. National Institute on Drug Abuse, NIDA. (2000) National Institutes of Health Principles of Drug Addiction Treatment. A Research-Based Guide. NIH Publication No. 00-4180.

48. Substance Abuse and Mental Health Services Administration, SAMHSA (2011) Interventions for Disruptive Behavior Disorders: How to Use the Evidence-Based Practices KITs. HHS Pub. No. SMA-11-4634, Rockville, MD U.S. Department of Health and Human Services, 
Citation: Kresina TF, Bruce RD, Pirard S, Mulvey K, Huesca RS, et al. (2012) International Expansion of the Use of Pharmacotherapies for the Treatment of Opioid Dependence. Clin Exp Pharmacol S5. doi:10.4172/2161-1459.S5-001

49. Substance Abuse and Mental Health Services Administration, (2007) SAMHSA. Guidelines for the Accreditation of Opioid Treatment Programs.

50. Kresina TF, Litwin A, Marion I, Lubran R, Clark HW. (2009) Federal government oversight and regulation of medication assisted treatment for the treatment of opioid dependence. J Drug Policy Anal 2: 1-23.

51. Code of Federal Regulations. Title 42. Part 8. Certification of opioid treatment programs. United States Government Printing Office, January 17, 2001.

52. Substance Abuse and Mental Health Services Administration, (2010) SAMHSA Medication Assisted Treatment for Opioid Addiction. 2010 State Profiles.

53. SAMHSA 2006 Substance Abuse and Mental Health Services Administration. The determinations report: A report on the physician waiver program established by the Drug Addiction Treatment Act of 2000. The SAMHSA Evaluation of the Impact of the DATA Waiver Program. Conducted under Task Order 277-00 6111. Rockville, MD

54. Substance Abuse and Mental Health Services Administration, SAMHSA Buprenorphine. Physician and Treatment Locator.

55. Substance Abuse and Mental Health Services Administration, SAMHSA (2004) Clinical guidelines for the use of buprenorphine in the treatment of opioid addiction. Treatment Improvement Protocol (TIP) 40. DHHS Publication No. 04-3939. Rockville Maryland.

56. Barry DT, Irwin KS, Jones ES, Becker WC, Tetrault JM, et al. (2009) Integrating buprenorphine treatment into office-based practice: a qualitative study. J Gen Intern Med 24: 218-225.

57. Thomas CP, Reif S, Haq S, Wallack SS, Hoyt A, et al. (2008) Use of buprenorphine for addiction treatment: perspectives of addiction specialists and general psychiatrists. Psychiatr Serv 59: 909-916.

58. Walley AY, Alperen JK, Cheng DM, Botticelli M, Castro-Donlan C, et al. (2008) Office-based management of opioid dependence with buprenorphine: clinical practices and barriers. J Gen Intern Med 23: 1393-1398.

59. Fiellin DA, O'Connor PG (2002) Clinical practice. Office-based treatment of opioid-dependent patients. N Engl J Med 347: 817-823.

60. Cheever LW, Kresina TF, Cajina A, Lubran R (2011) A model federal collaborative to increase patient access to buprenorphine treatment in HIV primary care. J Acquir Immune Defic Syndr 56: S3-S6.

61. United States Department of State. Bureau of International Narcotics and Law Enforcement Affairs. International Narcotics Control Strategy Report. 2011.

62. Encuesta Nacional De Adicciones 2008. Consejo Nacional contra las Adicciones.

63. Comision Nacional contra las Adicciones (CONADIC).

64. Centros de Integración Juvenil, A.C.

65. Profesionales contra la Adiccion. Methadone Treatment.

66. Profesionales contra la Adiccion. Methadone Treatment. Asistencia Medica Contra la Adiccion (AMCA)

67. http://www.opioids.com/offshorepharmacy/

68. Fischer B, Chin AT, Kuo I, Kirst M, Vlahov D (2002) Canadian illicit opiate users' views on methadone and other opiate prescription treatment: an exploratory qualitative study. Subst Use Misuse 37: 495-522.

69. Health Canada. The Use of Opioids in the Management of Opioid Dependence. 1992 ISBN: 0-662-59256-5

70. Latowsky M, Kallen E (1997) Mainstreaming methadone maintenance treatment: the role of the family physician. Can Med Assoc 157: 395-398.

71. Brands B, Blake J, Marsh D (2003) Impact of methadone program philosophy changes on early treatment outcomes. J Addict Dis 22: 19-38.

72. Berger P, Rachlis A, Peter A, Hettiarachchi D, Klein A,et al. The Canadian HIV Project Centre Ontario Primary Care Mentor Program. Final Evaluation. Int Conf AIDS. 1994 Aug 7-12; 10: 40 (abstract no. 134B/D).

73. CNW Newswire. CAMH releases buprenorphine guidelines for treatment of opioid dependence. November2, 2011.

74. The College of Physicians and Surgeons of Ontario. Buprenorphine hydrochloride for the treatment of opioid dependence.
75. Kahan M, Srivastava A, Ordean A, Cirone S (2011) Buprenorphine: new treatment of opioid addiction in primary care. Can Fam Physician 57: 281-289.

76. Lynch ME, Fischer B (2011) Prescription opioid abuse: What is the real problem and how do we fix it? Can Fam Physician 57: 1241-1242.

77. Fischer B, Nakamura N, Rush B, Rehm J, Urbanoski K (2010) Changes in and characteristics of admissions to treatment related to problematic prescription opioid use in Ontario, 2004-2009. Drug Alcohol Depend 109: 257-260.

78. Schechter MT, Kendall $P$ (2011) Is there a need for heroin substitution treatment in Vancouver's Downtown Eastside? Yes there is, and in many other places too. Can J Public Health 102: 87-89.

79. Kahan M (2009) Diacetylmorphine versus methadone for the treatment of opioid addiction. N Engl J Med 361: 2194.

80. Oviedo-Joekes E, Nosyk B, Marsh DC, Guh D, Brissette S, et al. (2009) Scientific and political challenges in North America's first randomized controlled trial of heroin-assisted treatment for severe heroin addiction: rationale and design of the NAOMI study. Clin Trials 6: 261-271.

81. Ferri M, Davoli M, Perucci CA (2010) Heroin maintenance for chronic heroindependent individuals. Cochrane Database Syst Rev 4: CD003410.

82. Farrell M, Verster A, Davoli M, Nilson M, Merino PP (2001) Reviewing current practice in drug-substitution treatment in the European Union. Luxembourg, European Monitoring Centre for Drugs and Drug Addiction.

83. European Monitoring Center for Drugs and Drug Addiction (EMCDDA) (2010) Annual report 2010: the state of the drugs problem in Europe; Opioid use and drug injection. EMCDDA, Libon, Portugal.

84. European Monitoring Center for Drugs and Drug Addiction (EMCDDA) Problem Drug Use (PDU). EMCDDA 2011, Libon, Portugal.

85. European Monitoring Center for Drugs and Drug Addiction (EMCDDA). Best practice portal: Treatment options for opioid users. EMCDDA 2011, Libon, Portugal.

86. European Monitoring Center for Drugs and Drug Addiction (EMCDDA) (2011) Drug treatment overviews. EMCDDA.

87. Reimer J, Verthein U, Karow A, Schafer I, Naber D, et al. (2011) Physical and mental health in severe opioid-dependent patients within a randomized controlled maintenance treatment trial. Addiction 106:1647-1655.

88. European Monitoring Center for Drugs and Drug Addiction (EMCDDA). Health and social responses. EMCDDA 2010, Libon, Portugal.

89. Mannelli P, Peindl KS, Wu LT (2011) Pharmacological enhancement of naltrexone treatment for opioid dependence: a review. Subst Abuse Rehabil 2011: 113-123

90. RefindYourWay.com. Naltrexone implants in Europe. 2011.

91. Jegu J, Gallini A, Soler P, Montastruc JL, Lapeyre-Mestre M (2011) Slowrelease oral morphine for opioid maintenance treatment: a systematic review. $\mathrm{Br} \mathrm{J}$ Clin Pharmacol 71: 832-843.

92. Kruglov YV, Kobyshcha YV, Salyuk T, Varetska O, Shakarishvili A, et al. (2008) The most severe HIV epidemic in Europe: Ukraine's national HIV prevalence estimates for 2007. Sex Transm Infect 84: i37-i41.

93. UNAIDS.Ukraine July 2008. Country Situation.

94. Ukraine AIDS Alliance. Road Map on Scaling-up Towards Universal Access to HIVIAIDS Prevention, Treatment, Care and Support in Ukraine by 2010.

95. Golovanevskaya M (2011) Ukraine: Stop police abuse of methadone patients Open Society Foundation Blog.

96. Cook C, Kanaef N (2008) The Global State of Harm Reduction in 2008. London: International Harm Reduction Association, 34.

97. UNAIDS (2011) Methadone substitution therapy helps prevent new HIV infection in Belarus.

98. Holt E (2010) Russian injected drug use soars in face of political inertia. Lance 376: 13-14.

99. Baker SL Jr (1972) U.S. Army heroin abuse identification program in Vietnam implications for a methadone program. Am J Public Health 62: 857-860.

100. Newman RG, Whitehill WB (1979) Double-blind comparison of methadone and placebo maintenance treatments of narcotic addicts in Hong Kong. Lancet 2: $485-488$. 
Citation: Kresina TF, Bruce RD, Pirard S, Mulvey K, Huesca RS, et al. (2012) International Expansion of the Use of Pharmacotherapies for the Treatment of Opioid Dependence. Clin Exp Pharmacol S5. doi:10.4172/2161-1459.S5-001

101. National Institute of Hygiene and Epidemiology, Ministry of Health Vietnam. HIVISTI Integrated Biological and Behavioral Surveillance (IBBS) in Vietnam, $2005-2006$.

102.Liu EW, Liang T, Shen LM, Zhong H, Wang B, et al. (2010) [Impact of methadone maintenance treatment on HIV risk behaviors of heroin drug users]. Zhonghua Yu Fang Yi Xue Za Zhi 44: 981-984.

103. Kresina TF, Bruce RD, McCance-Katz EF (2009) Medication assisted treatment in the treatment of drug abuse and dependence in HIVIAIDS infected drug users. Curr HIV Res 7: 254-364.

104.Sun X, Lu F, Wu Z, Poundstone K, Zeng G, et al. (2010) Evolution of information-driven HIVIAIDS policies in China. Int J Epidemiol 39: ii4-ii13.

105. Yin W, Hao Y, Sun X, Gong X, Li F, et al. (2010) Scaling up the national methadone maintenance treatment program in China: achievements and challenges. Int J Epidemiol 39: ii29-ii37.

106. Li J, Ha TH, Zhang C, Liu H (2010) The Chinese government's response to drug use and HIVIAIDS: a review of policies and programs. Harm Reduct $J$ 7: 4 .

107.Du WJ, Xiang YT, Wang ZM, Chi Y, Zheng Y, et al. (2008) Socio-demographic and clinical characteristics of 3129 heroin users in the first methadone maintenance treatment clinic in China. Drug Alcohol Depend 94: 158-164.

108. Lucas GM, Beauchamp G, Aramrattana A, Shao Y, Liu W, et al. (2011) Shortterm safety of buprenorphine/naloxone in HIV-seronegative opioid-dependent Chinese and Thai drug injectors enrolled in HIV Prevention Trials Network 058. Int J Drug Policy.

109. Chan R. Taiwan's HIV approach serves as example for APEC. Taiwan Today 08/19/2011.

110. Ching-fang C, Wu S DOH plans to introduce methadone treatment in prison . Focus Taiwan 04/07/1010.

111. Multicentre trial of Suboxone in opiate-dependent subject in Taiwan.

112. Mulvey KP, Nguyen TMN, Nguyen T N (2010) Setting up Nationwide Methadone Maintenance Therapy Program: A Vietnam Case Study. Presented at the Asia Regional Injection Drug Use Conference, Ho Chi Minh City, Vietnam Nov 6-10.

113. Viet Nam News. Nation steps up methadone treatment for heroin addicts. May $5,2010$.

114. IRIN. UN Office for the Coordination of Humanitarian Affairs. CAMBODIA: Government opens first methadone clinic. September 17, 2010.

115. Ali R Independent Evaluation of the Pilot Methadone Maintenance Therapy Program in Cambodia, University of Adelaide, August 2011.

116. CMHDD 2011: Data from the records of the MMT Clinic, Center for Mental Health \& Drug Dependence, Khmer-Soviet Friendship Hospital, Phnom Penh, July 2011.

117. McAuthur M (1999) A history of methadone treatment in Australia: The influence of social control arguments in its development. Paper presented at the History of Crime, Policing and Punishment Conference convened by the Australian Institute of Criminology in conjunction with Charles Sturt University and held in Canberra, 9-10.

118. Byrne A, Wodak A (1996) Census of patients receiving methadone treatment in a general practice. Addict Res 3: 341-9.

119. Program Profile. New South Wales (Australia) Prison Methadone Maintenance Program. Crime Solutions.gov Office of Justice Programs. US Department of Justice.

120. National Policy on Methadone Treatment. Commonwealth of Australia. 1997.

121. Ministerial Council on Drug Strategy. National Drug Strategy 2010-2015. A framework for action on alcohol, tobacco and other drugs. Australian Government . Department of Health and Ageing. 25 February 2011. ISBN 978-1-74241-406-5 Online ISBN: 978-1-74241-407-2 Publications Number: D0224.

This article was originally published in a special issue, Treatment for Drug use Disorders handled by Editor(s). Dr. Peter R. Martin, Vanderbilt Psychiatric Hospital, USA
122. Scarborough J, Eliott J, Braunack-Mayer A (2011) Opioid substitution therapy. A study of GP participation in prescribing. Aust Fam Physic; 40: 241-245.

123. Gil JS, Sulaiman AH, Habil MH (2007) The first methadone programme in Malaysia: overcoming obstacles and achieving the impossible. ASEAN J Psychiat 8: 64-70.

124. Norsiah A, Dharmananda S, Nazri M, Marzafuan MM, Lee BWH, et al. (2010) Can primary care clinic run MMT service well? Malaysian Fam Physic 5: 1923.

125. Al Jazerra English. Malaysia mosque offers drug therapy.

126. Schottenfeld RS, Chawarski MC, Mazlan M (2008) Maintenance treatment with buprenorphine and naltrexone for heroin dependence in Malaysia: randomised, double-blind, placebo-controlled trial. Lancet 371: 2192-2200.

127. United Nations Office on Drug and Crime (UNODC) . Myanmar. What works reviewing harm reduction responses in Myanmar. June 2010.

128. United Nations Office on Drug and Crime (UNODC). New methadone maintenance therapy programme launched in muse, Myanmar. March 26, 2010.

129. Natpratan C Methadone maintenance and harm reduction in Northern Thailand.

130. Lawrinson P, Ali R, Buavirat A, Chiamwongpaet S, Dvoryak S, et al. (2008) Key findings from the WHO collaborative study on substitution therapy for opioid dependence and HIVIAIDS. Addiction 103: 1484-1492.

131. Mathers B, Degenhart L, Phillips B et al [2008] Global epidemiology of injecting drug use and HIV among people who inject drugs: A systematic review. Lance 372: 1733-1745.

132. Larance B, Ambekar A, Azim T, Murthy P, Panda S, et al. (2011) The availability, diversion and injection of pharmaceutical opioids in South Asia Drug Alcohol Rev 30: 246-254.

133.De S, Jain R, Ray R, Dhawan A, Varghese ST (2008) Assessment of differential doses of buprenorphine for long term pharmacotherapy among opiate dependent subjects. Indian J Physiol Pharmacol 52: 53-63.

134. Kumar MS, Natale RD, Langkham B, Sharma C, Kabi R, et al. (2009) Opioid substitution treatment with sublingual buprenorphine in Manipur and Nagaland in Northeast India: what has been established needs to be continued and expanded. Harm Reduct J 6: 4.

135. Mokri A (2002) Brief overview of the status of drug abuse in Iran.

136. Khachatrian A (2009) Uzbekistan: government discontinues pilot opiate substitution therapy program. HIV AIDS Policy Law Rev 14: 26-27.

137. McCurdy SA, Ross MW, Kilonzo GP, Leshabari MT, Williams ML (2006) HIV AIDS and injection drug use in the neighborhoods of Dar es Salaam, Tanzania Drug Alcohol Depend 82 Suppl 1: S23-27.

138. Williams ML, McCurdy SA, Bowen AM, Kilonzo GP, Atkinson JS, et al. (2009) HIV seroprevalence in a sample of Tanzanian intravenous drug users. AIDS Educ Prev 21: 474-483. 